\title{
Recovery of polycyclic aromatic hydrocarbons and their oxygenated derivatives in contaminated soils using aminopropyl silica solid phase extraction
}

Coren Pulleyblank ${ }^{\mathrm{a}, \mathrm{b}}$, Brian Kelleher $^{\mathrm{a}}$, Pablo Campo ${ }^{\mathrm{b}}$, Frederic Coulon $^{\mathrm{b} *}$,

${ }^{a}$ Dublin City University, School of Chemical Sciences, Glasnevin, Dublin 9, Ireland

${ }^{\mathrm{b}}$ Cranfield University, School of Water, Energy and Environment, Cranfield, UK

Corresponding author: Frederic Coulon

School of Water, Energy and Environment,

Vincent Building, Cranfield University,

Bedford MK43 0AL

Tel direct: $+44(0) 1234754981$

Fax $+44(0) 1234751671$

Email: f.coulon@cranfield.ac.uk 


\section{Abstract}

The formation, fate, and toxicology of oxy-, hydroxy-, and carboxy- substituted PAH (OPAH, OHPAH, COOHPAH, respectively) alongside PAH in contaminated soils have received increasing attention over the past two decades; however, there are still to date no standardized methods available for their identification and quantitation in soil. Here we investigated and developed the first method using aminopropylsilica solid phase extraction (SPE) for these compounds. We further investigated the efficacy of the developed method for three soils representing a range of contamination levels and soil textural characteristics and evaluated the impact of different sample preparation steps on the recovery of targeted compounds. Average recovery of PAH, OPAH, and OHPAH standards were $99 \%, 84 \%$, and $86 \%$, respectively for the SPE method. In contrast, COOHPAH exhibited the lowest recovery $(0-82 \%)$ and poor inter-batch reproducibility. Soil texture and contamination levels influenced full method efficiency. Specifically, soils with higher proportion of clay contributed to the loss of the higher molecular weight OHPAH prior to SPE. Soil with the highest contamination showed enhanced recovery of some lower-concentration mid weight $\mathrm{PAH}$ and $\mathrm{OPAH}$, while the least contaminated soil showed greater sensitivity to evaporative losses during sample preparation. Recommendations for reducing matrix effects as well as the practice of using deuterated PAH surrogate standards for OPAH analysis are further discussed. Quantitation of recovered PAH and oxygenated PAH across the three soils showed high reproducibility ( $<10 \%$ relative standard deviation for a majority of compounds), supporting the use of this method for PAH, OPAH, and OHPAH at contaminated sites.

Keywords: Polycyclic Aromatic Hydrocarbons, oxy-PAH, hydroxy-PAH, solid phase extraction, aminopropyl silica, soil analysis 


\section{Introduction}

Polycyclic aromatic hydrocarbons (PAH) are among the most widely reported persistent organic pollutants contributing to risks associated with petroleum- and industriallycontaminated soils. A substantial body of research has shed light on the fate and transport of PAH in the environment as well as their toxic effects to both on human health and other ecological receptors (Abdel-Shafy and Mansour, 2016). Information garnered to date has enhanced decision making for remediation and management of sites contaminated with PAH (Alegbeleye et al., 2017). However, studies have also demonstrated that efforts to remediate PAH-contaminated soils sometimes lead to increases in toxicity despite notable reductions in concentrations of the targeted PAH compounds (Chibwe et al., 2015; Jiang et al., 2016). Soils contaminated with PAH contain significant amounts of other polycyclic aromatic compounds, including PAH that have been transformed through substitution of polar carbonyl, hydroxyl, and/or carboxyl groups (OPAH, OHPAH, and COOHPAH, respectively) onto the aromatic ring structure through photo-, chemical, or biological oxidative processes (Andersson and Achten, 2015). Critically, there is growing awareness that some of these oxygenated PAH transformation products may be more toxic and carcinogenic than the parent compounds (Knecht et al., 2013; Schrlau et al., 2017), and that remediation approaches that allow the build-up of these compounds could contribute to additional risks for receptors at or downstream from contaminated sites (Andersson et al., 2003; Chibwe et al., 2015; Hu et al., 2014; Lundstedt et al., 2006).

While a greater understanding of transformation products with a range of chemistries could improve decision making at contaminated sites (Lundstedt et al., 2007), this research is currently hampered by a lack of standard protocols for identifying and 
quantifying these compounds in soils (Pulleyblank et al., 2019, for extended review and references). Effort has been made towards routinizing OPAH analysis in soils (Lundstedt et al., 2014), with the most typical approach involving extraction of the soil with dichloromethane, hexane, or hexane/acetone, followed by a clean-up or fractionation step over silica using column chromatography or solid phase extraction (SPE) in order to remove interferents and/or fractionate $\mathrm{PAH}$ and $\mathrm{OPAH}$. The use of broad specificity solvents and/or multiple cycles during the extraction stage offers the opportunity to identify a greater number of analytes through extension of the subsequent preparative chromatography to isolate more polar fractions. Fractionation also offers the opportunity for analysing different compound classes using, e.g., different derivatization or instrumental methods. However, only a few studies have described methods for the separation of OHPAH and COOHPAH alongside PAH and OPAH in whole-soil extracts (Bandowe and Wilcke, 2010; Chibwe et al., 2015; Letzel et al., 2001; Meyer et al., 1999), and there has been little broader uptake in the use of these methods (Pulleyblank et al. 2019). Further work is needed to address specific limitations of available methods such as uncertain quantitative performance (Chibwe et al., 2015; Meyer et al., 2013), uncertainty in the best application of surrogate recovery compounds, low recovery of OHPAH and COOHPAH (Bandowe and Wilcke, 2010), and/or the amount of material and complexity of the methods (Chibwe et al., 2015; Meyer et al., 1999). In addition, available soils-based methods have thus far reported recovery of oxygenated PAH from standard solutions or single spiked uncontaminated soils (Bandowe and Wilcke, 2010, Meyer et al., 1999). Yet even amongst soils, variations in soil texture and contamination level may also be expected to affect the identification and quantitative recovery of target analytes. Many studies also have not reported recovery for individual stages of sample preparation. A greater understanding of method performance across multiple preparative 
stages and soil types could reduce uncertainties in method applicability, help focus efforts to improve the most relevant steps of the protocols and increase adoption and standardization of methods.

Existing methods targeting one or more class of oxygenated PAH in crude soil extracts have utilized silica, alumina, polymeric, or strong base sorbents, sometimes in combination (Pulleyblank et al., 2019). To date, the utility of weak base aminopropyl silica for the fractionation of PAH, OPAH, OHPAH and COOHPAH from soil extracts has not been investigated. Retention characteristics of aminopropyl silica are primarily influenced by the terminal primary amine group which increases hydrogen bonding capacity and offers basic functionality that can be modulated by adjusting eluent $\mathrm{pH}$ and solvent polarity. The capacity of aminopropyl silica to allow the separation of a wide range of neutral, polar, and acidic lipids in crude sediment extracts has been demonstrated (Murphy et al., 2016; Pinkart et al., 1998), suggesting it could also be applied to enhance separation of oxygenated PAH of multiple functionalities while using a single sorbent phase. An SPE method using aminopropyl silica has been proposed for the separation of nitro-substituted and oxygenated PAH in aerosol samples (Cochran et al., 2012). However limited data have been presented for the recovery of oxygenated PAH and the use of methanol for the elution of OHPAH requires a full dry-down and solvent exchange step prior to derivatization, which may contribute unnecessarily to analyte loss. At the same time, protocols developed for alternate sample types may not be suitable for soils due to the possibility of substantial matrix effects (Avagyan et al., 2015; Cochran et al., 2012) .

Therefore, our aim was to investigate the use of aminopropyl silica SPE for the fractionation of target PAH and their transformation products in crude soil extracts, specifically isolating three fractions for subsequent GC-MS analysis: (A) less polar PAH 
and OPAH which can be analysed together without requiring derivatization; (B) moderately polar compounds, OHPAH and related natural non-acidic phenolic compounds requiring derivatization, but avoiding solvent exchange via sample dry down; and $(\mathrm{C})$ acidic transformation products, including $\mathrm{COOHPAH}$ and related acidic phenolic compounds, which requires removal of protic, acidic, or basic solvents prior to derivatization via silylation (Schummer et al., 2009). We further investigated the application of the method to three soil matrix types, presenting the first study to consider the impacts of soil textural class and contamination level on the method recovery of this broad range of polar aromatic compounds. In order to elucidate factors affecting the selected methodology, this study separately examined recovery and the effect of matrix using a four-stage approach:

Stage 1: SPE method development using analytical standards: comparison of eluents, load volumes, linearity tests, consideration of post-SPE evaporative losses;

Stage 2: testing the SPE method with pre-prepared soil extracts spiked with target analytes (hereafter Matrix-SPE tests); comparison of three soils and standards. This helped elucidate whether other constituents in the soil extracts specifically influence recovery of the SPE method, e.g. through competition for sorption sites, and the extent to which whole-method recovery is affected at the SPE stage;

Stage 3: full method recovery testing - analytes spiked into soil prior to extraction; comparison of recovery for three soils. When combined with stage 2 results, this helped elucidate the extent to which losses occur during the extraction stage including specific matrix-associated effects; and,

Stage 4: Qualitative and quantitative characterization of the original unspiked soils.

Surrogate standards are 
Finally, surrogate standards, i.e. compounds of known concentration and similar chemistry to target analytes, typically isotopically labelled, are frequently added prior to extraction or SPE. By tracking the amount of surrogate lost (or gained), the recovery of related target analytes can be estimated, and/or final target analyte concentrations may be adjusted or "corrected" for losses/ gains/ matrix effects introduced during sample processing. Although the availability of deuterated OPAH internal or surrogate standards is improving, these compounds are not widely available, and there is uncertainty in their best use during OPAH analysis (Pulleyblank et al., 2019). In the meantime, more readily available deuterated PAH are sometimes used as surrogates estimating OPAH recovery or correcting for losses during sample preparation (Obrist et al. 2015). We investigated the impact of using deuterated PAH to estimate losses of OPAH during each stage of the study in order to evaluate this practice.

\section{Materials and Methods}

\subsection{Chemical reagents and Materials}

Target PAH, transformation products, and internal standards were obtained from SigmaAldrich UK including 13 2.5-6 ring PAH in EPA semi volatile mix B (Table 1). Supelco Discovery aminopropyl silica SPE columns $(500 \mathrm{mg} / 3 \mathrm{~mL})$, derivatization agent $\mathrm{N}, \mathrm{O}$ Bis(trimethylsilyl)trifluoroacetamide (BSTFA) with $1 \%$ trimethylchlorosilane (TMCS), sodium sulfate, hydrochloric acid $(\mathrm{HCl})$, and triethylamine (TEA) were also obtained from Sigma Aldrich UK. Deuterated PAH used for surrogate recovery were obtained as a mixture $(2000 \mu \mathrm{g} / \mathrm{mL}$ each in acetone) from Thames Restek, UK. Solvents hexane (HEX), dichloromethane (DCM), acetone (ACE), acetonitrile (ACN) methanol (MeOH) were analytical reagent grade or higher and were obtained from Fischer Scientific, UK. Amber vials used for extraction and SPE eluent collection were acid washed, rinsed with deionized water, then furnaced at $450{ }^{\circ} \mathrm{C}$ for $4 \mathrm{~h}$ to remove residual organic materials. 
Volumetric glassware used during the preparation of standards, spike solutions, and samples, was rinsed 3x in acetone and 3x in the 'incoming' solvent and was wrapped in foil below the fill line in order block excess light which can cause transformation of aromatic compounds (Woudneh et al., 2016). PTFE lined screwcaps were rinsed 3x with acetone prior to use.

\subsection{Soil characteristics}

In order to consider the influence of soil matrix on SPE method performance, three soils with varying texture and contamination level were investigated (Table 2). Soils 1 and 2 were contaminated soils obtained from former gasworks sites in the southern UK. Soil 3 was obtained from a residential garden area in Bedford UK (10-15 cm depth) to provide comparison to a relatively uncontaminated soil. Soils were loosely wrapped in foil and air dried overnight, then ground and sieved to $2 \mathrm{~mm}$ and stored frozen at $-80^{\circ} \mathrm{C}$ before further analysis. Soil $\mathrm{pH}$ was measured in $0.01 \mathrm{M} \mathrm{CaCl}_{2}$ (5:1 liquid:solid) following ISO procedure 10390 (2005). Total soil organic matter was determined as loss on ignition (LOI): oven dried soils $\left(24 \mathrm{~h} 105^{\circ} \mathrm{C}\right)$ were heated to $450^{\circ} \mathrm{C}$ for $5 \mathrm{~h}$ to ash organic material, and the mass lost was calculated as a percentage of the total oven-dried mass (Institution, 2000). Soil was determined by sieving and sedimentation procedure (ISO 11277, 2009; Natural England TIN037 2008). Total carbon-TC and total nitrogen-TN were determined through combustion-elemental analysis using a Vario EL III Element Analyzer (BS-EN 13654-2, 2001). 
Table 2: Basic soil characteristics for three test soils

\begin{tabular}{|c|c|c|c|c|c|c|c|c|c|c|}
\hline Soil & Location (UK) & $\begin{array}{l}\text { Contamination } \\
\text { level }\end{array}$ & $\begin{array}{l}\text { Soil } \\
\text { texture }\end{array}$ & $\begin{array}{l}\text { Sand } \\
\%\end{array}$ & $\begin{array}{l}\text { Silt } \\
\%\end{array}$ & $\begin{array}{l}\text { Clay } \\
\%\end{array}$ & $\begin{array}{l}\text { LOI } \\
\%\end{array}$ & $\begin{array}{l}\mathrm{TC} \\
\%\end{array}$ & $\begin{array}{l}\mathrm{TN} \\
\%\end{array}$ & $\begin{array}{l}\mathrm{pH} \\
\mathrm{CaCl}_{2}\end{array}$ \\
\hline Soil 1 & $\begin{array}{l}\text { Kent } \\
\text { former gasworks }\end{array}$ & $\begin{array}{l}\text { very high, } \\
\text { strong tar odour }\end{array}$ & $\begin{array}{l}\text { coarse } \\
\text { sand }\end{array}$ & 88.3 & 8.1 & 3.6 & 20.1 & 18.3 & 0.4 & 8.4 \\
\hline Soil 2 & $\begin{array}{l}\text { Northamptonshire } \\
\text { former gasworks }\end{array}$ & moderately high & $\begin{array}{l}\text { fine sandy } \\
\text { loam }\end{array}$ & 51.8 & 22.8 & 25.3 & 8.1 & 5.8 & 0.2 & 7.4 \\
\hline Soil 3 & $\begin{array}{l}\text { Bedford } \\
\text { garden soil }\end{array}$ & very low & clay & 31.6 & 28.8 & 39.6 & 11.0 & -- & -- & 7.2 \\
\hline
\end{tabular}

\subsection{Stage 1: Development of SPE fractionation protocol using analytical standards}

The final SPE method is illustrated in Figure 1b. All SPE tests were performed using a vacuum manifold. For each cycle, gravity feed was used until only hold up volume remained, after which a gentle vacuum was applied to elute residual solvent. This provided more consistent flow rates in our setup than continual use of the vacuum pump. For all tests, SPE blanks were prepared using all materials but no 'load' solution.

During method development, several eluent systems were tested to optimize recovery of analytical standards. Each cartridge was conditioned with $6 \mathrm{~mL}$ of the first test eluent, then loaded with $100 \mu \mathrm{L}$ of a test spike mixture containing $20 \mu \mathrm{g} / \mathrm{mL}$ each target analyte (PAHM) and $5 \mu \mathrm{g} / \mathrm{mL}$ each deuterated PAH (PAHd) in 1:1 DCM:ACN. Eluent selection was considered using a sequential process, where the preferred solvent system for fraction A was selected then used first during eluent selection for fraction $\mathrm{B}$, and both these systems applied prior to testing eluents for fraction C. For each fraction, two full column volumes $(6 \mathrm{~mL})$ were used. Protic solvents such as methanol, which have been used in previous methods for the elution of OHPAH, were avoided for fraction $\mathrm{B}$ in order to eliminate solvent exchange prior to derivatization and reduce associated analyte loss. Eluents tested were as follows: for fraction A, HEX, DCM, and HEX:DCM (9:1); for fraction $\mathrm{B}, \mathrm{ACE}, \mathrm{ACN}$, and $4 \mathrm{~mL} \mathrm{ACE}$ followed by $2 \mathrm{~mL} \mathrm{ACN} \mathrm{(ACE+ACN);} \mathrm{for} \mathrm{fraction}$ $\mathrm{C}, 0.5 \% \mathrm{HCl}$ in $\mathrm{MeOH}$, and in $\mathrm{ACE}, \mathrm{ACN}$, and $\mathrm{ACE}: \mathrm{H}_{2} \mathrm{O}(9: 1)$, as well as 
ACE: $\mathrm{H}_{2} \mathrm{O}: \mathrm{TEA}(90: 10: 0.05)$ and $\mathrm{ACN}: \mathrm{H}_{2} \mathrm{O}: \mathrm{TEA}(90: 10: 0.05)$. Fraction $\mathrm{C}$ tests with $\mathrm{HCl}$ and no water were conducted in duplicate, while all other tests were conducted in triplicate. For eluent selection tests, post-SPE processing was conducted as in Figure 1c, with the exception that fraction A was also derivatized in order to detect early-eluting OHPAH, and fraction B was not subject to further concentration under $\mathrm{N}_{2}$.

After final selection of the eluent system, increased load volumes of $1 \mathrm{~mL}$ and $500 \mu \mathrm{L}$ were tested, but this led to early elution of $\mathrm{OHPAH}$ in fraction $\mathrm{A}$, so $100 \mu \mathrm{L}$ was maintained for all subsequent experiments. The linearity of the method was investigated through triplicate tests of PAHM at 10, 1, 0.1, and $0 \mu \mathrm{g} / \mathrm{mL}$ (as blanks), each with $5 \mu \mathrm{g} / \mathrm{mL}$ PAHd. As genuine samples would often require further concentration for the analysis of transformation products, fractions $\mathrm{A}$ and $\mathrm{B}$ were further reduced to $1 \mathrm{~mL}$ under $\mathrm{N}_{2}$ prior to instrumental analysis.

\subsection{Preparation of soil extracts for Stages $2-4$ :}

The preparation of soil extracts using ultrasonic assisted extraction is shown in Figure 1a. Preliminary tests using $1 \mathrm{~g}$ soil demonstrated that Soil 1 extracts became very tarry and difficult to re-suspend after initial concentration. Therefore, a $0.5 \mathrm{~g}$ mass was selected and used for all soils to maintain consistency during these tests. Each sample was extracted in two cycles, first with $10 \mathrm{~mL}$ DCM, then with $10 \mathrm{~mL}$ ACN to target polar transformation products (Wang et al., 2012). The supernatants from each extraction cycle were combined and reduced to $1 \mathrm{~mL}$ then topped with an additional $1 \mathrm{~mL} \mathrm{DCM}$ and sonicated briefly in order to re-suspend materials which had collected on vessel walls during the concentration steps and to maintain consistency of the 1:1 ACN:DCM load solvent system used for all SPE tests. All extractions, including blanks (all reagents except soil), were conducted in triplicate. 


\subsection{Stage 2: Matrix-SPE tests - testing the SPE-method with spiked soil extracts}

To investigate the effect of the soil matrices on target analyte recoveries through the SPE method alone, $1 \mathrm{~mL}$ of each previously-prepared concentrated soil extract as well as 1:1 ACN:DCM solvent standard were spiked to obtain added concentrations of $20 \mu \mathrm{g} / \mathrm{mL}$ PAHM and $5 \mu \mathrm{g} / \mathrm{mL}$ PAHd (see Figure 1- starred point 1). An additional $1 \mathrm{~mL}$ each soil extract/solvent standard was spiked with $5 \mu \mathrm{g} / \mathrm{mL}$ PAHd only in order to account for any target analytes already present in the soil extract/blank. Triplicate $100 \mu \mathrm{L}$ aliquots were then processed as in Figure 1b-c.

\subsection{Stage 3 and 4: Full method recovery tests and quantitation in soils}

In order to investigate the recovery and the effect of the soil matrices on the full method $($ extraction + SPE), triplicate samples of each soil were spiked prior to extraction (Figure 1- starred point 2) to yield target added soil concentrations of $20 \mu \mathrm{g} / \mathrm{g}$ PAHM and $8 \mu \mathrm{g} / \mathrm{g}$ PAHd, respectively. PAHM spike levels reflect a mid-range concentration of OPAH previously reported in industrially contaminated soils (Arp et al., 2014). An additional set of samples was spiked with the PAHd mixture only to quantify contaminants present in the original soils. Six samples were also prepared with sodium sulfate and the same spike solutions to assist characterization of losses independent of the presence of soil matrix, and as extraction blanks. During sample preparation, an additional 3 samples for each soil of approximately $1 \mathrm{~g}$ each were used to obtain moisture content at the time of analysis (as percent mass difference after oven drying $105^{\circ} \mathrm{C}$ for $24 \mathrm{~h}$ ). The average moisture content was used to calculate final dry-mass analyte concentrations. 
Table 1: GC-MS method for target PAH and oxygenated transformation products

\begin{tabular}{|c|c|c|c|c|c|c|c|c|c|}
\hline Target analyte & CAS no. & $\begin{array}{l}\text { Mass } \\
\mathrm{g} / \mathrm{mol}\end{array}$ & $\begin{array}{l}\text { SR } \\
\text { grp } 1\end{array}$ & $\begin{array}{l}\mathrm{RT} \\
\min \end{array}$ & $\begin{array}{l}\mathrm{SIM} \mathrm{m} / \mathrm{z} \\
\text { quant., ref }\end{array}$ & $\mathrm{R}^{2}$ & $\begin{array}{l}\mathrm{LOD}^{2} \\
(\mu \mathrm{g} / \mathrm{mL})\end{array}$ & $\begin{array}{l}\mathrm{LOQ}^{2} \\
(\mu \mathrm{g} / \mathrm{mL})\end{array}$ & Fig. $4^{3}$ \\
\hline \multicolumn{10}{|l|}{ PAH } \\
\hline Naphthalene & $91-20-3$ & 128.2 & SR1 & 7.79 & 128,64 & 0.999 & 0.009 & 0.030 & $\mathrm{a}$ \\
\hline Acenaphthylene & $208-96-8$ & 152.2 & SR2 & 12.34 & $\mathbf{1 5 2}, 126$ & 0.999 & 0.003 & 0.012 & $\mathrm{~b}$ \\
\hline Fluorene & $86-73-7$ & 166.2 & SR2 & 14.37 & 166,83 & 0.999 & 0.004 & 0.013 & $\mathrm{c}$ \\
\hline Phenanthrene & $85-01-8$ & 178.2 & SR3 & 17.22 & $\mathbf{1 7 8}, 89$ & 0.998 & 0.005 & 0.017 & $\mathrm{~d}$ \\
\hline Anthracene & $120-12-7$ & 178.2 & SR3 & 17.38 & $\mathbf{1 7 8}, 89$ & 0.998 & 0.004 & 0.013 & $\mathrm{e}$ \\
\hline Pyrene & 129-00-0 & 202.3 & SR3 & 22.90 & 202, 101 & 0.999 & 0.003 & 0.009 & $\mathrm{f}$ \\
\hline Benz[a]anthracene & $56-55-3$ & 228.3 & SR4 & 29.80 & 228, 114 & 0.998 & 0.001 & 0.004 & $\mathrm{~g}$ \\
\hline Chrysene & 218-01-9 & 228.3 & SR4 & 30.11 & 228, 114 & 0.998 & 0.001 & 0.004 & $\mathrm{~h}$ \\
\hline Benzo[b]fluoranthene & $205-99-2$ & 252.3 & SR5 & 36.78 & $\mathbf{2 5 2}, 126$ & 0.998 & 0.002 & 0.006 & $\mathrm{j}$ \\
\hline Benzo[k]fluoranthene & 207-08-9 & 252.3 & SR5 & 36.92 & $\mathbf{2 5 2}, 126$ & 0.997 & 0.003 & 0.009 & $\mathrm{k}$ \\
\hline Benzo[a]pyrene & 218-01-9 & 252.3 & SR5 & 38.69 & 252, 126 & 0.997 & 0.002 & 0.006 & 1 \\
\hline Indeno[1,2,3-cd]pyrene & $193-39-5$ & 276.3 & SR5 & 45.21 & 276, 138 & 0.999 & 0.002 & 0.008 & $\mathrm{~m}$ \\
\hline Dibenz[a,h]anthracene & $53-70-3$ & 276.3 & SR5 & 45.48 & $\mathbf{2 7 8}, 139$ & 0.999 & 0.004 & 0.015 & $\mathrm{n}$ \\
\hline Benzo[ghi]perylene & $191-24-2$ & 276.3 & SR5 & 46.52 & 276, 138 & 0.999 & 0.003 & 0.009 & o \\
\hline \multicolumn{10}{|l|}{ ОРАН } \\
\hline 1-Indanone & $83-33-0$ & 132.2 & SR1 & 9.431 & 132, 104 & 0.999 & 0.002 & 0.007 & $\mathrm{p}$ \\
\hline 9-Fluorenone ${ }^{4}$ & $486-25-9$ & 180.2 & SR2 & 16.60 & 180,152 & 0.999 & 0.002 & 0.006 & $\mathrm{q}$ \\
\hline 9,10-Anthraquinone & $84-65-1$ & 208.2 & SR3 & 20.24 & 208, 180 & 0.999 & 0.002 & 0.007 & $\mathrm{r}$ \\
\hline 9,10-Phenanthrenequinone & $84-11-7$ & 208.2 & -- & 24.21 & 208, 180 & $\mathrm{nq}^{5}$ & $\mathrm{nq}$ & $\mathrm{nq}$ & - \\
\hline \multicolumn{10}{|l|}{ ОНРАН } \\
\hline Catechol & $120-80-9$ & 110.1 & & 9.98 & 254,151 & 0.999 & 0.003 & 0.011 & $n d^{6}$ \\
\hline 1-Hydroxynaphthalene & $1779-10-8$ & 144.2 & & 13.65 & 216, 201 & 0.999 & 0.003 & 0.011 & $\mathrm{~s}$ \\
\hline 1-Hydroxyacenaphthene & $6306-07-6$ & 170.1 & & 16.85 & $\mathbf{2 4 2}, 152$ & 0.999 & 0.001 & 0.004 & $\mathrm{t}$ \\
\hline 9-Hydroxyfluorene & 1689-64-1 & 182.2 & & 17.45 & 254,165 & 0.999 & 0.001 & 0.004 & $\mathrm{u}$ \\
\hline 9-Hydroxyphenanthrene & $484-17-3$ & 194.2 & & 22.45 & 266, 251 & 0.999 & 0.002 & 0.008 & $\mathrm{w}$ \\
\hline 1-Hydroxypyrene & $5315-79-7$ & 218.3 & & 30.41 & 290,175 & 0.998 & 0.003 & 0.010 & $\mathrm{x}$ \\
\hline \multicolumn{10}{|l|}{ Phenolic aldehydes } \\
\hline 4-Hydroxybenzaldehyde & $123-08-0$ & 122.1 & & 10.90 & 179, 151 & 0.999 & 0.003 & 0.010 & A \\
\hline Vanillin & $121-33-5$ & 152.1 & & 13.52 & 194,201 & 0.999 & 0.003 & 0.009 & B \\
\hline \multicolumn{10}{|l|}{ СООНРАН } \\
\hline 1-Naphthylacetic acid & $86-87-3$ & 186.1 & & 17.00 & 258, 168 & 0.999 & 0.059 & 0.197 & $\mathrm{C}$ \\
\hline Fluorene-9-carboxylic acid & 1989-33-9 & 210.2 & & 19.58 & 282,165 & $\mathrm{nq}$ & nq & $\mathrm{nq}$ & - \\
\hline 1-Hydrox-2-naphthoic acid & $86-48-6$ & 188.2 & & 20.45 & $\mathbf{3 1 7}, 243$ & 0.996 & 0.001 & 0.004 & $\mathrm{D}$ \\
\hline \multicolumn{10}{|l|}{ Phenolic Acids } \\
\hline Salicylic acid & $69-72-7$ & 138.1 & & 13.15 & 267, 209 & 0.999 & 0.004 & 0.014 & $\mathrm{E}$ \\
\hline 4-Hydroxybenzoic acid & $99-96-7$ & 138.1 & & 14.83 & $\mathbf{2 6 7}, 193$ & 0.999 & 0.026 & 0.087 & $\mathrm{~F}$ \\
\hline 2,5-Dihydroxybenzoic acid & 490-79-9 & 154.1 & & 16.98 & $\mathbf{3 5 5}, 297$ & 0.999 & 0.001 & 0.004 & G \\
\hline Ferulic acid & $1135-24-6$ & 194.2 & & 22.17 & 338, 323 & 0.998 & 0.010 & 0.036 & $\mathrm{H}$ \\
\hline \multicolumn{10}{|l|}{$\begin{array}{l}\text { Deuterated PAH for } \\
\text { surrogate recovery (SR) }\end{array}$} \\
\hline SR1- Naphthalene-d8 & $1146-35-2$ & 136.2 & & 7.75 & 136, 108 & na & na & na & $\mathrm{i}$ \\
\hline SR2- Acenaphthene-d 10 & $15067-26-2$ & 164.3 & & 12.86 & $\mathbf{1 6 4}, 162$ & na & na & na & ii \\
\hline SR3- Phenanthrene-d ${ }_{10}$ & $1517-22-2$ & 188.3 & & 17.22 & 188, 160 & na & na & na & iii \\
\hline SR4- Chrysene-d 12 & $1719-03-5$ & 240.4 & & 30.00 & $\mathbf{2 4 0}, 120$ & na & na & na & iv \\
\hline SR5- Perylene-d 12 & $1520-96-3$ & 264.4 & & 39.08 & $\mathbf{2 6 4}, 132$ & na & na & na & $\mathrm{v}$ \\
\hline \multicolumn{10}{|l|}{ Internal standards } \\
\hline Nonadecane----d40 & $39756-36-0$ & 308.8 & & 18.12 & 66, 98 & na & na & na & $\mathrm{I}$ \\
\hline Triacontane $-\mathrm{d}_{62}$ & $93952-07-9$ & 485.2 & & 40.37 & 66, 98 & na & na & na & II \\
\hline
\end{tabular}




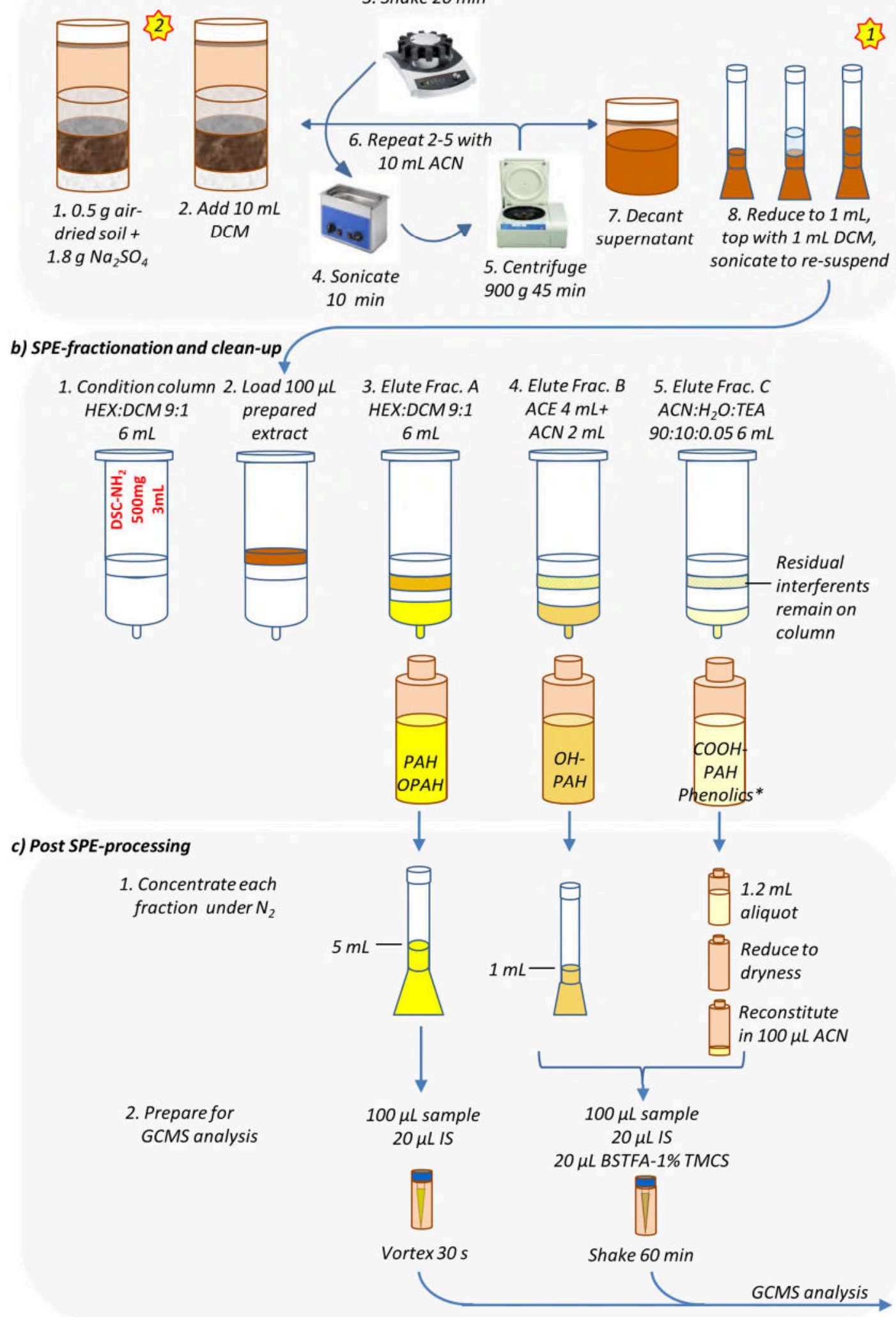

Figure 1: Method for the analysis of PAH and their oxygenated derivatives in crude soil extracts using aminopropyl silica SPE: a) extraction b) fractionation and clean-up, c) postSPE processing. Gold stars 1 and 2 indicate points where spiked compounds were added to assess recovery from Matrix-SPE tests and full method-recovery respectively. *qualitative analysis. 


\subsection{GC-MS analysis}

Target compounds were analysed by GC-EI-MS (Shimadzu TQ-8040) with AOC-6000 autosampler and Lab Insight Solutions software (Shimadzu, 2015-2016). Compound separation was achieved using a 30 m Rtx-5 column (5\% diphenyl/95\% dimethylpolysiloxane $0.25 \mathrm{~mm}$ i.d., $0.25 \mu \mathrm{m} \mathrm{df}$ ). Instrument settings were as follows injection port: $200{ }^{\circ} \mathrm{C}, 1 \mu \mathrm{L}$ injections, splitless mode; column flow, $36 \mathrm{cms}^{-1}$; oven program: initial temperature $80{ }^{\circ} \mathrm{C}$, increasing $5{ }^{\circ} \mathrm{C} \mathrm{min}^{-1}$ to $100{ }^{\circ} \mathrm{C}$, then $8{ }^{\circ} \mathrm{C} \mathrm{min}^{-1}$ to $200{ }^{\circ} \mathrm{C}$, and $3{ }^{\circ} \mathrm{C} \min ^{-1}$ to $300{ }^{\circ} \mathrm{C}$, hold for $2 \mathrm{~min}$; transfer line and MS system: $300{ }^{\circ} \mathrm{C}$; EI: $70 \mathrm{eV} \mathrm{SCAN} \mathrm{/SIM} \mathrm{mode,} \mathrm{event} \mathrm{times} \mathrm{of} 0.3 \mathrm{~s}$ and $0.060 \mathrm{~s}$ respectively.

To prepare samples for analysis, $100 \mu \mathrm{L}$ sample and $20 \mu \mathrm{L}$ of internal standard (IS) mixture $\left(20 \mu \mathrm{g} / \mathrm{mL}\right.$ nonadecane- $\mathrm{d}_{40}$ and triacontane- $\left.\mathrm{d}_{62}\right)$ were added to a $200 \mu \mathrm{L}$ glass insert inside a $2 \mathrm{~mL}$ amber glass GC vial then capped (silicone/PTFE) and shaken to combine. For samples requiring derivatization, $20 \mu \mathrm{L}$ of BSTFA $1 \%$ TMCS was also added, and vials were shaken at room temperature for 60 min. BSTFA reacts with hydroxyl and carboxyl groups, to form trimethylsilyl (TMS) derivatives; this increases the volatility of polar compounds allowing for their analysis by GC-MS.

PAH and OPAH were identified as the $\mathrm{M}^{\cdot+}$ ion, while OHPAH, COOHPAH, and phenolic compounds were identified as their trimethylsilyl derivatives (SIM-monitored ions are given in Table 1). A compound was considered identified if the retention time deviated $<0.1 \mathrm{~min}$ from the standard, the ratio of quantitative and reference ion differed less than $30 \%$ of the analytical standard, and other ions present in the overall mass pattern showed good visual agreement with the standard spectrum. Reference check mixtures containing all analytes were run with each experiment in order to monitor for any shifts in retention time or substantive changes in instrument sensitivity. Derivatized samples were also 
monitored for the presence of residual underivatized target compounds. SPE and full method blanks were also checked for interferences, and an additional blank injection was included every 10 samples to monitor for instrument carry over. Any contribution of a target $\mathrm{m} / \mathrm{z}$ value over the specified integration period in a blank sample was subtracted from experimental samples prior to the calculation of recovery.

External instrument calibration was conducted using the internal standard (IS) method with four point calibration curves $(0.01-10 \mu \mathrm{g} / \mathrm{mL})$, with $0 \mu \mathrm{g} / \mathrm{mL}$ serving as a blank. PAH and OPAH were prepared in DCM, while all other analytes were prepared in ACN with derivatization. By introducing an internal standard with known concentration, it is possible to monitor and normalize GC-MS signals to account for any changes in injection volume or instrument sensitivity for a given run. Ideally each analyte would be normalized to the signal of its isotopically labelled counterpart; however in practice this is not feasible, and it is most important that the concentration-dependent signal of the target analyte and the internal standard is consistent during instrument calibration (i.e. the IS-normalized calibration curve is consistent and linear). In this study, deuterated alkanes were used as the internal standards while deuterated aromatic compounds were prioritized for use as surrogate compounds to monitor losses/gains throughout the extraction and fractionation procedures. It should be noted that recovery of surrogate compounds also accounts for any differences in instrument response introduced by the matrix, and that when an analyte signal is also adjusted by the recovery of the surrogate, the signal - and chemistry - of the internal standard becomes mathematically irrelevant. Limits of detection (LOD) and quantitation (LOQ) were established through calculation of, respectively, 3 and 10 times the standard deviation of the IS-normalized signal from seven replicate injections of the $0.01 \mu \mathrm{g} / \mathrm{mL}$ calibration solution divided by the slope of the calibration curve. 


\subsection{Calculations}

All post-processing was conducted in Microsoft Excel (2010) or in Matlab (2018b Academic License) using custom scripts incorporating common functions (mean, standard deviation) and linear regression analysis using the fitlm function. Recovery of the target analyte and surrogate deuterated PAH was calculated as follows:

$$
\operatorname{Rec}_{t}=\frac{\left(m_{t}-m_{u}\right) * d f}{m_{r}} \times 100 \% \quad \operatorname{Rec}_{S}=\frac{\left(m_{s}\right) * d f}{m_{r}} \times 100 \%
$$

where $\operatorname{Rec}_{t}$ and $\operatorname{Rec}_{\mathrm{s}}$ are the recovery of the target and surrogate respectively; $\mathrm{m}_{\mathrm{t}}$ is the mass of analyte in the test sample; $\mathrm{m}_{\mathrm{u}}$ is the mass of the analyte or interference equivalent in the unspiked sample or blank- in soil extraction tests, $\mathrm{m}_{\mathrm{t}}$ and $\mathrm{m}_{\mathrm{u}}$ were normalized to the mass of soil extracted in each replicate; $\mathrm{m}_{\mathrm{s}}$ is the mass of the surrogate in the sample, $\mathrm{m}_{\mathrm{r}}$ is the mass of the analyte in the reference load solution; and $\mathrm{df}$ is the relative dilution factor between the test sample and the reference load solution.

Where application of a correction factor for surrogate recovery was used, it was calculated as follows:

$$
\operatorname{Rec}_{S R}=\frac{\operatorname{Rec}_{t}}{\operatorname{Rec}_{S}} \times 100 \%
$$

where RecsR is the recovery of the target adjusted for surrogate recovery. Surrogateadjusted values are denoted by the subscript SR 


\section{Results and discussion}

\subsection{GC-MS method performance}

The majority of the target analytes demonstrated good linearity over the calibration range $\left(\mathrm{R}^{2}>0.997\right.$; Table 1$)$. Limits of detection were comparable to or lower than previously reported values for EI-SIM-MS for this range of compounds (Cochran et al., 2012). Two compounds were considered to give non-quantitative results: fluorene-9-carboxylic acid, which yielded the reduced transformation product 9-fluorenone, and phenanthrenequinone, which was only observed at the highest concentration levels, and which has been reported elsewhere to exhibit rearrangement including the formation of 9-fluorenone (Bandowe and Wilcke, 2010). Therefore, while 9-fluorenone showed strong quantitative behaviour throughout the recovery experiments, the positive identification and quantitation of 9-fluorenone is treated here with caution, as it may reflect the presence of multiple compounds in actual samples. Potential contributors to the quantitation of 9fluorenone in this study would be chemically consistent with elution in fraction A, primarily PAH and OPAH.

\subsection{Development of the SPE protocol}

All solvent mixtures provided satisfactory recoveries with average recovery for total PAH ranging between 102 and 104\% (Figure 2), and for individual PAH between 82\% (naphthalene-DCM) and 126\% (benzo[ghi]perylene-DCM). Average recovery of larger OPAH ranged between 82 and 90\%, but was comparatively poor for 1-indanone, which was also somewhat adversely impacted when surrogate adjustment was applied (46-51\% vs. $40-49 \%$ SR). 

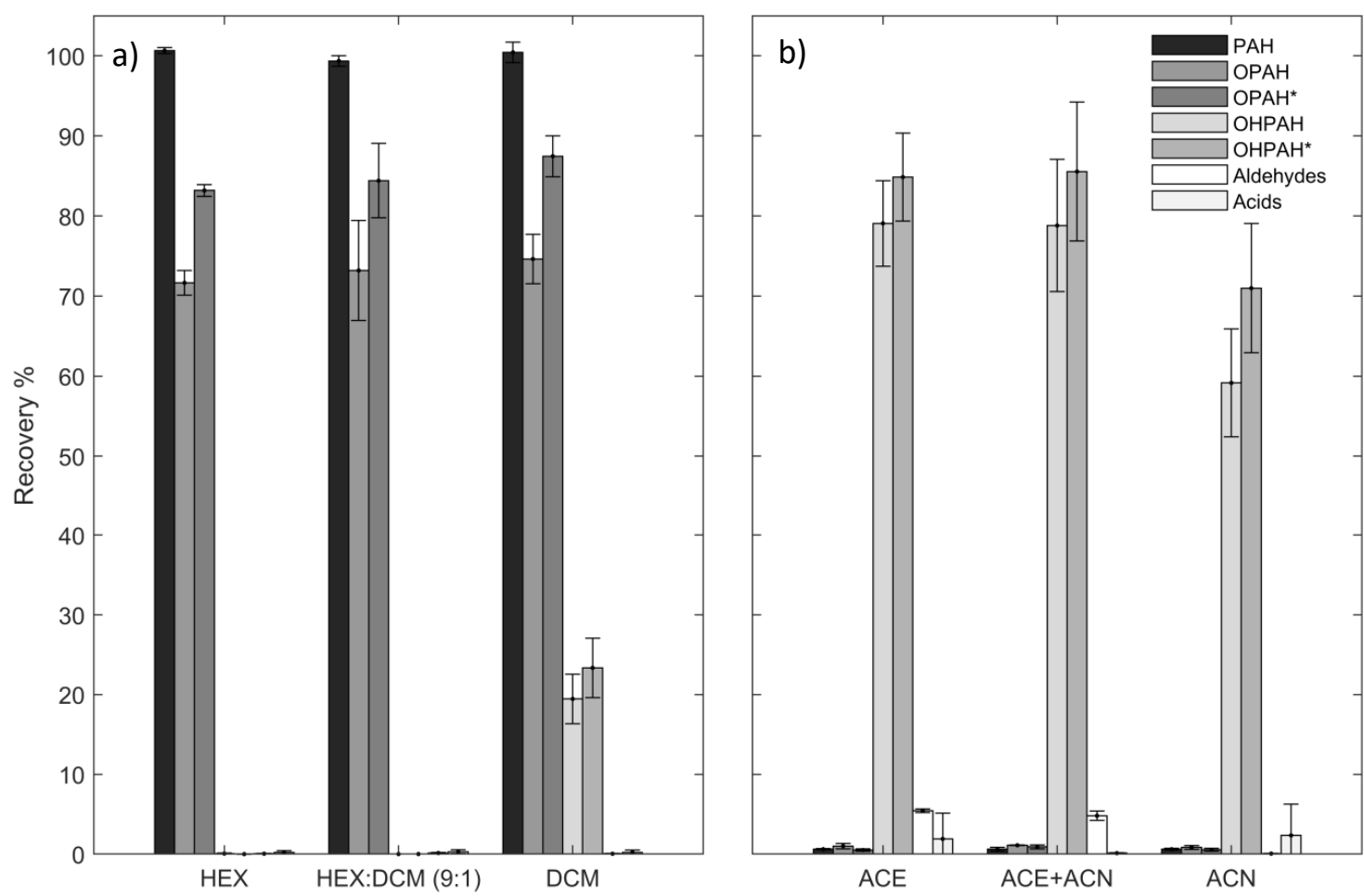

Figure 2: Average recovery of target $\mathrm{PAH}$ and derivative groups during solvent selection method development phase targeting a) Fraction A: PAH, and OPAH, and b) fraction B: OHPAH. Both fractions were derivatized with BSTFA in order to quantify polar compounds during this stage. Asterisked series omit the most volatile component: i.e. OPAH* omits 1-indanone, and $\mathrm{OHPAH}^{*}$ omits catechol. Error bars indicate the standard deviation of the summary recovery of all analytes included in each group from triplicate SPE trials.

It should be noted that further tests discussed below demonstrated improved recovery of 1-indanone when BSTFA derivatization was not used. DCM improved recovery of OPAH but led to the premature elution of OHPAH when used as sole eluent. As HEX and HEX:DCM 9:1 offered comparable results in these tests, the latter was selected since the addition of DCM improved recovery of 1-indanone specifically, and the inclusion of a more polar solvent is often recommended for PAH and OPAH analysis (Lundstedt et al., 2014). 
For OHPAH, the inclusion of ACE in the eluent system substantially improved recoveries over the use of ACN alone, with average recovery increasing by $15-20 \%$, and recovery of catechol specifically increasing by $45-50 \%$. In the ACE and ACE+ACN systems, average recoveries were respectively, for 1-hydroxynaphthalene 108 and 106\%, mid weight OHPAH (1-hydroxyacenaphthene, 9-hydroxyfluorene, and 9hydroxyphenanthrene) 82 and 85\%, and heavier weight OHPAH (1-hydroxypyrene) 66 and $63 \%$. As the two systems provided comparable results, the ACE-ACN system was selected because ACN is recommended for promoting the derivatization of OHPAH (Schummer et al., 2009) and may be useful in reducing excessive volatilization of analytes during concentration steps as it evaporates more slowly than acetone.

It was initially thought that all non-acidic phenolic compounds would elute in fraction B along with catechol, however 4-hydroxybenzaldehyde and vanillin did not follow this pattern. With typically less than 5\% recovery of these compounds in the OHPAH fraction and no further elution in fraction $\mathrm{C}$ using initial $\mathrm{HCl}+$ solvent eluents, it was supposed that the aldehyde group might be bonding covalently with amino groups on the SPE sorbent to form Schiff bases, which is a reversible reaction in the presence of water and $\mathrm{H}^{+}$or $\mathrm{OH}^{-}$(Nomura and Jones, 2013). As the use of acid-only-modified solvents initially tested for fraction $\mathrm{C}$ yielded poor recoveries of both target acids and phenolic aldehydes $(<2 \%)$, three additional systems were tested, one incorporating water into the $\mathrm{HCl}-\mathrm{ACN}$ eluent system and two incorporating water and TEA, ACN: $\mathrm{H}_{2} \mathrm{O}: \mathrm{TEA}$ (90:10:0.05) and ACE: $\mathrm{H}_{2} \mathrm{O}:$ TEA (90:10:0.05). Both TEA-modified systems substantially improved the recovery of 4-hydroxybenzaldehyde, though total recovery was still low (15-20\%), and marginally improved the recovery of vanillin (3-7\%). The $\mathrm{ACN}: \mathrm{H}_{2} \mathrm{O}: \mathrm{TEA}$ system also yielded the best recoveries for salicylic acid (58+-11\%), gentisic acid (38+- 9.1\%), and 1-hydroxy-2-naphthoic acid (82 +/- 7.4\%), offering apparent method improvements over 
a previous extraction+silica SPE protocol where recovery of these compounds was $<10 \%$ (Bandowe and Wilcke, 2010). The presence of 9-fluorenone in the $\mathrm{ACN}: \mathrm{H}_{2} \mathrm{O}$ :TEA system, despite its strong recovery in fraction A and its absence in fraction B, also suggests elution of fluorene-9-carboxylic acid. Other acid analytes, 4-hydroxybenzoic acid, ferulic acid, and 1-naphthylacetic acid, were not recovered. As analyte loss might occur during the final evaporation and the solvent exchange step required for BSTFA derivatization, the recovery for this procedure was also independently tested $(n=3)$. Negligible losses were observed for 1-hydroxy-2-naphthoic acid and ferulic acid, but all other targets exhibited losses between 27 and $45 \%$, indicating that this solvent exchange step likely accounts for the lower recovery of some, if not all, phenolic aldehyde and acid analytes. Although the $\mathrm{ACN}: \mathrm{H}_{2} \mathrm{O}: \mathrm{TEA}$ mixture provided the best results of the eluents tested, further tests of this system revealed poor inter-batch repeatability. This fraction is therefore not considered suitable for quantitative analysis by GC-MS, but it might be used qualitatively to suggest the presence of acid and phenolic aldehyde PAH transformation products of interest for further analysis, and has therefore been included here in further method investigations. The use of an alternative derivatization technique or HPLC may extend the analytical utility of this SPE fraction (Meyer et al., 1999). However, further testing was beyond the scope of the present study.

Results presented in Table 3 for PAH indicate that the method showed strong linearity for concentrations of PAH, OPAH, and OHPAH in the load range $0.1 \mu \mathrm{g} / \mathrm{mL}-10 \mu \mathrm{g} / \mathrm{mL}$. High $\mathrm{R}^{2}$ and low error of the calibration slope was achieved for both absolute, and especially for surrogate-corrected values, including improvements for OPAH quantitation.

Table 3: SPE linearity tests for $0.01-10 \mu \mathrm{g} / \mathrm{mL}$ target analyte. Lower limits of linearity are based on a reduction of the final extract to $1 \mathrm{~mL}$ as tested. All correlations are significant $(\mathrm{p}<0.001)$ 


\begin{tabular}{|c|c|c|c|c|}
\hline Target analyte & $\mathrm{R}^{2}$ & $\mathrm{R}^{2} \mathrm{SR}$ & $\mathrm{SE}_{\mathrm{m}} / \mathrm{m}^{1}$ & $\mathrm{SE}_{\mathrm{m}} / \mathrm{m}_{\mathrm{SR}}{ }^{1}$ \\
\hline \multicolumn{5}{|l|}{ PAH } \\
\hline Naphthalene & 0.975 & 0.999 & 0.0438 & 0.0024 \\
\hline Acenaphthylene & 0.973 & 0.999 & 0.0456 & 0.0027 \\
\hline Fluorene & 0.970 & 0.999 & 0.0483 & 0.0079 \\
\hline Phenanthrene & 0.967 & 0.999 & 0.0506 & 0.0022 \\
\hline Anthracene & 0.970 & 0.999 & 0.0483 & 0.0039 \\
\hline Pyrene & 0.965 & 0.999 & 0.0517 & 0.0067 \\
\hline Benz[a]anthracene & 0.945 & 0.999 & 0.0655 & 0.0023 \\
\hline Chrysene & 0.944 & 0.999 & 0.0661 & 0.0049 \\
\hline Benzo[b]fluoranthene & 0.951 & 0.999 & 0.0618 & 0.0037 \\
\hline Benzo[k]fluoranthene & 0.943 & 0.999 & 0.0668 & 0.0084 \\
\hline Benzo[a]pyrene & 0.952 & 0.999 & 0.0609 & 0.0026 \\
\hline Indeno[1,2,3-cd]pyrene & 0.948 & 0.998 & 0.0638 & 0.0158 \\
\hline Dibenz $[\mathrm{a}, \mathrm{h}]$ anthracene & 0.944 & 0.999 & 0.0662 & 0.0131 \\
\hline Benzo[ghi]perylene & 0.946 & 0.998 & 0.0653 & 0.0177 \\
\hline \multicolumn{5}{|l|}{ OPAH } \\
\hline 1-Indanone & 0.973 & 0.999 & 0.0456 & 0.0076 \\
\hline 9-Fluorenone & 0.965 & 0.998 & 0.0519 & 0.0152 \\
\hline 9,10-Anthraquinone & 0.955 & 0.998 & 0.0593 & 0.0186 \\
\hline \multicolumn{5}{|l|}{ ОНРАН } \\
\hline Catechol & 0.947 & & 0.0670 & \\
\hline 1-Hydroxynaphthalene & 0.992 & & 0.0245 & \\
\hline 1-Hydroxyacenaphthene & 0.987 & & 0.0312 & \\
\hline 9-Hydroxyfluorene & 0.994 & & 0.0219 & \\
\hline 9-Hydroxyphenanthrene & 0.993 & & 0.0226 & \\
\hline 1-Hydroxypyrene & 0.989 & & 0.0288 & \\
\hline
\end{tabular}

\subsection{Stage 2: Matrix-SPE tests}

Figure 3 displays recovery values for surrogates and OPAH obtained from Fraction A and

B of matrix-SPE tests. Absolute recovery of all analytes tended to be lower for the standards and Soil 3 than for Soil 2 and especially Soil 1. This was notable for the 4-6 ring PAHs, 9-fluorenone, 9,10- anthraquinone, and most OHPAH. It is possible that the presence of a more complex matrix improved the preservation of the targets in solution by offering competition to sorption sites on glassware, reducing the rate of solvent evaporation during concentration steps, and/or through the presence of natural antioxidant compounds (Woudneh et al., 2016).

Recoveries for Fraction A PAH surrogates and larger OPAH in Soils 1 and 2 were typically in an acceptable analytical range $(<20 \%$ deviation from $100 \%)$ and relative 
standard deviation (1-10\%). Exceptions were observed for Soil 1, where RSD for 9,10anthraquinone was somewhat higher (15\%), and elevated absolute recoveries near $150 \%$, were obtained for both 9-fluorenone and acenaphthene- $\mathrm{d}_{10}$. This indicated that matrixassociated baseline signal variation may be an issue for quantitation especially of 2.5 ring aromatic compounds in this soil (i.e. causing overestimation in spiked samples and/or underestimation in unspiked samples). In this case, it was demonstrated that matrix effects for PAH could be largely controlled by using surrogate recovery as an adjustment factor (e.g. absolute acenaphthylene recovery was $147 \pm 20 \%$ but with adjustment was $95 \pm 5$ \%sR). Surrogate recovery adjustment also improved quantitation of PAH in Soil 3 and standards (recovery values closer to $100 \%$ and reduced RSD). Application of PAHd surrogate adjustment to OPAH recovery during matrix SPE tests tended to reduce RSD, suggesting that factors affecting surrogate recovery may also help explain partial variability in OPAH measurement. Due to recoveries of acenaphthene- $\mathrm{d}_{10}$ and phenanthrene- $\mathrm{d}_{10}$ near $100 \%$ for Soils 2,3 , and standards, surrogate recovery adjustment had marginal impacts on mean recovery of 9-fluorenone and 9, 10-anthraquinone in these matrices ( $<3 \%$ difference between unadjusted and adjusted values); however, adjustment offered substantial improvements to interpretation of Soil 1. For 1-indanone, application of the surrogate adjustment factor led to greater deviation from $100 \%$ in all cases, suggesting that additional or different factors inhibit the recovery of this compound in SPE-matrix tests compared to naphthalene- $\mathrm{d}_{8}$ to an extent that the recovery of the latter does not reflect the recovery of the former. 

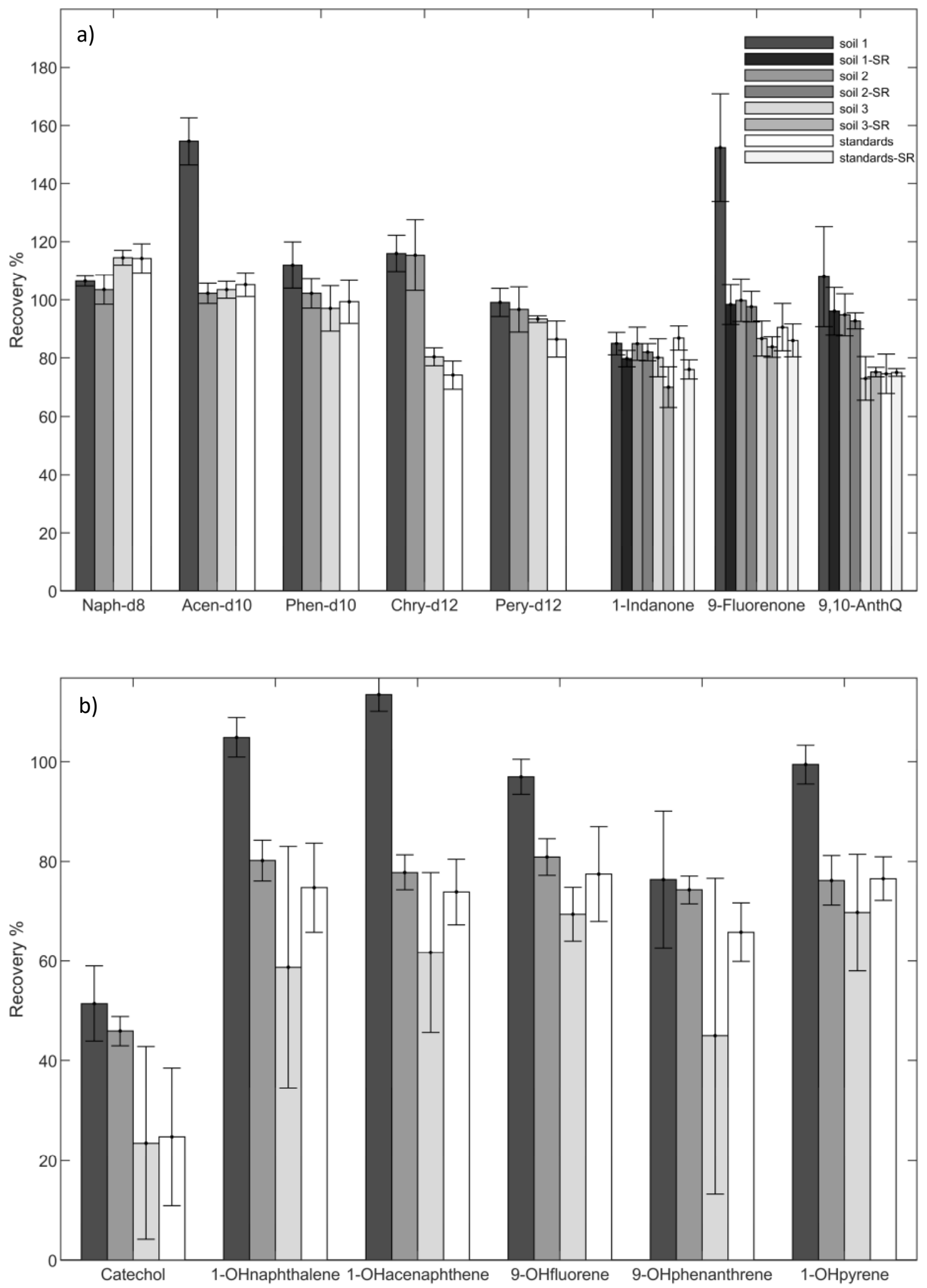

Figure 3: Average recovery of PAH surrogates, OPAH, OHPAH from Matrix-SPE tests in a) Fraction A, with and without the application of surrogate recovery adjustment for OPAH (SR series); b) Fraction B. Error bars indicate the standard deviation of recovery from triplicate Matrix-SPE trials. 
In addition to impacts on calculated recovery of the spiked analytes, the complexity of the Soil 1 matrix also contributed to late elution of some high-concentration PAH in fraction B, typically less than $5 \%$ of the combined analyte signal of Fractions A and B. Increasing the proportion of DCM by up to $50 \%$ in the first eluent, as suggested by Cochran et al. (2012) might reduce this effect for the most contaminated soils.

For fraction B, the average recovery of OHPAH excluding catechol, ranged between 63 and $113 \%$, with most recovery values between 70 and $85 \%$. RSD across matrix-SPE tests was generally $<10 \%$, except for Soil 1 where both apparent recovery and variability were greater. The somewhat lower recovery values obtained here when compared to original solvent selection experiment may be due to the addition of the evaporationconcentration step. Separate testing of the evaporation step $(n=3)$ indicated this could alone account for target losses of up to $33,30,20,19,8$, and $14 \%$ for catechol, 1 -

hydroxynaphthalene, 1-hydroxyacenaphthene, 9-hydroxyfluorene, $\quad 9$ hydroxyphenanthrene, and 1-hydroxypyrene, respectively, and could explain 2-10\% of the relative standard deviation in OHPAH recoveries. The consistency of the pattern observed across all OHPAH except catechol suggests that the use of a deuterated midweight hydroxylated PAH surrogate could be useful for the quantitation of these compounds at the SPE stage. With the exception of some catechol, carryover of OHPAH to fraction $\mathrm{C}$ was not observed.

\subsection{Stage 3: Full method recovery tests}

The recovery of target analytes after full method tests (Table 4) demonstrated greater variability than SPE-matrix tests, which was expected due to the inherent heterogeneity of soil and greater number of steps involved in sample preparation (Gerlach and 
Nocerino, 2003). For standards and Soil 3, the average recoveries of PAH and deuterated surrogates were generally very good (77-129\%), with the exception of enhanced recovery of SR4 compounds, observed across all matrices, as well as lower recovery and greater variability for the more volatile compounds in SR groups 1 and 2. For Soils 1 and 2, despite low RSD in concentrations $(<10 \%$ for most PAH), at the high concentrations of specific PAH present in the original soils, this variability exceeded and thus masked the contribution of the spike used for recovery calculation, leading to calculated values not representative of true extraction recovery (e.g. $>400 \%$ and /or negative values). The PAH calculated recoveries impacted specifically in this way have been marked not representative, 'NR', in Table 3. In most cases, the recovery of the associated deuterated surrogate indicated that the method had similar recovery to Soil 3. In some cases, very high recovery values obtained for the surrogate suggest the presence of residual matrix enhancement effects e.g. for mid-weight PAH (SR2-SR4) in Soil 1 and to a lesser extent in Soil 2. However, strong agreement between final quantitation for mid-weight PAH using this method and alternate analysis using simple DCM extraction (agreement within 1-15\% without surrogate adjustment, data not shown) suggests matrix enhancements may have impacted lower-concentration analytes including surrogates, but did not substantially impact quantitation of high-concentration PAH (2-3 orders of magnitude higher) reported here.

Recovery of OPAH followed similar trends to PAH. Strong recoveries were obtained for standards and Soil 3, while Soil 1 yielded non-representative values due to elevated concentrations which masked the spike contribution. For Soil 2, the OPAH enhanced recovery is likely attributed to the residual matrix effects also observed for lowerconcentration PAH in groups SR2-SR4. Surrogate recovery adjustment increased RSD and had a negative effect on calculated recovery for both 1-indanone and 9-fluorenone in 
standards, Soil 2, and Soil 3, but tended to reduce RSD and improve calculated recovery for 9-fluorenone in Soil 1 and 9, 10-anthaquinone in all soils. In the latter cases, where surrogate adjustment offered improvements during recovery tests, the benefit of using this factor during final quantitation was ambiguous: adjustment either increased RSD, or did not substantially impact final quantitation. The inconsistencies and lack of clear benefit observed in these tests suggest use of the deuterated PAH as surrogates for tracking full-method recovery and quantitation of OPAH in soils is not suitable as a general approach.

The recovery of OHPAH for standards generally ranged between 68 and 89\%, agreeing within $\sim 10 \%$ with the matrix-SPE tests, with the exception of catechol, which was not recovered in any of the extraction-SPE tests. For the recovered OHPAH, deviations from the matrix-SPE recovery levels were greater when soil was present in the extraction (vs. standards in $\mathrm{Na}_{2} \mathrm{SO}_{4}$ ) and demonstrated different trends related to specific analyte and soil type. It is possible that the presence of a more complex matrix improved the preservation of 1-hydroxyacenaphthene and 9-hydroxyfluorene in solution as suggested during the matrix-SPE tests, with further enhancements for Soil 1 following trends for mid-weight PAH and OPAH in Fraction A. This does not appear to hold for the other OHPAH. In the case of 1-hydroxynaphthalene (recoveries ranging between 31 and 77\%), the trend may reflect a trade-off between increased preservative effect of the more complex matrices and the more extended evaporation period required to concentrate highly contaminated sample extracts prior to SPE. It could also be related to the differential sorption on soil particles. For 1-hydroxypyrene and especially 9hydroxyphenanthrene, the range of recoveries across soil types was substantial (30-81\% and 11-145\%, respectively), and did not follow a clear trend associated with contamination level or preparative evaporation time. Instead, particularly low recovery of 
these compounds for Soil 2 and 3 can be best explained by the substantial and increasing proportion of clay in the soil mass (Biswas et al., 2015). The small size of clay particles as well as specific structure and charge characteristics of the minerals offers substantial sorptive capacity in soils even for non-polar PAH, and may also restrict the extractability of related aromatic compounds (Biswas et al., 2015). Low recovery of 9hydroxyphenanthrene from clay soils has also been reported by Bandowe and Wilke (2010). As 9-hydroxyphenanthrene and 9-hydroxypyrene displayed similar trends in soil extractions, the use of deuterated hydroxy-pyrene as a surrogate could improve quantitation of both compounds without leading to overestimation of 9hydroxyphenanthrene. Similarly, use of a 2.5-ring deuterated OHPAH could help track recovery could improve quantitation of 1-hydroxyacenaphthene and 9-hydroxyfluorene.

With the exception of lower recovery of 1-hydroxypyrene, this method offered a comparable or better range of OHPAH recoveries to those reported in previous methods targeting only OHPAH using methanol extraction followed by silica-SPE (Avagyan et al., 2015), or using water+ACN extraction followed by C18-SPE or dispersive liquid liquid microextraction and GC-MS (Wang et al., 2012). In comparison to methods targeting a range of functionalities, this method demonstrated elevated recovery of a greater number of target OHPAH when compared to accelerated solvent extraction (ASE) + silica clean-up and GC-MS analysis (Bandowe and Wilcke, 2010), especially when the contaminated soils presented here are considered. Improvements over the ASE-silica method were substantial for 9-hydroxyfluorene specifically (91\% vs 60\%), and were similar to those obtained using a Soxhlet extraction and silica/strong base clean up step followed by HPLC analysis (93 \%) (Meyer et al., 1999). Recoveries of hydroxynaphthalenes for the current method were within range of and in some cases higher (by $\sim 10-40 \%$ ), than those presented in the ASE-silica method but were lower compared to 
the Soxhlet-silica/strong base/HPLC approach. Although the coarser texture of soil used in the development of the latter method may have improved recovery of these compounds through reduced sorption, our investigation also suggests that particle size shifts are not the primary controlling factor for recovery of 1-hydroxynaphthalene, and more likely, the evaporative step included prior to preparative chromatography is responsible for losses observed here.

\subsection{Stage 4: Characterization of unspiked tests soils}

\subsubsection{Qualitative identification of polyaromatic compounds}

SPE offered substantial clean-up and fractionation capacities for the analysis of PAH, OPAH, and OHPAH in uncontaminated and contaminated soils (Figure 4). In the most contaminated soils, target breakdown products were difficult to detect in whole extracts even when these compounds were spiked directly into the extract, as in the load solutions for matrix-SPE tests. Interferences in the complex soil matrix led to poor chromatographic resolution (Figure 4a), obscurance of analyte mass spectral pattern, and possibly limited derivatization or ionization of these compounds. Fractionation assisted the identification of target compounds in these soils, which would otherwise not have passed detection criteria. In the unspiked sample presented in Figure 4, only 2 of 5 target OHPAH detected in fraction $\mathrm{B}$, and only 2 of 6 (or of 7 if the presence of 9-fluorenone is indicative of fluorene-9-carboxylic acid) acid transformation products detected in fraction $\mathrm{C}$ were identified in the derivatized whole extract. The reduction of interferents in fraction $\mathrm{A}$ also improved signals for 9-fluorenone and 9,10- anthraquinone. 

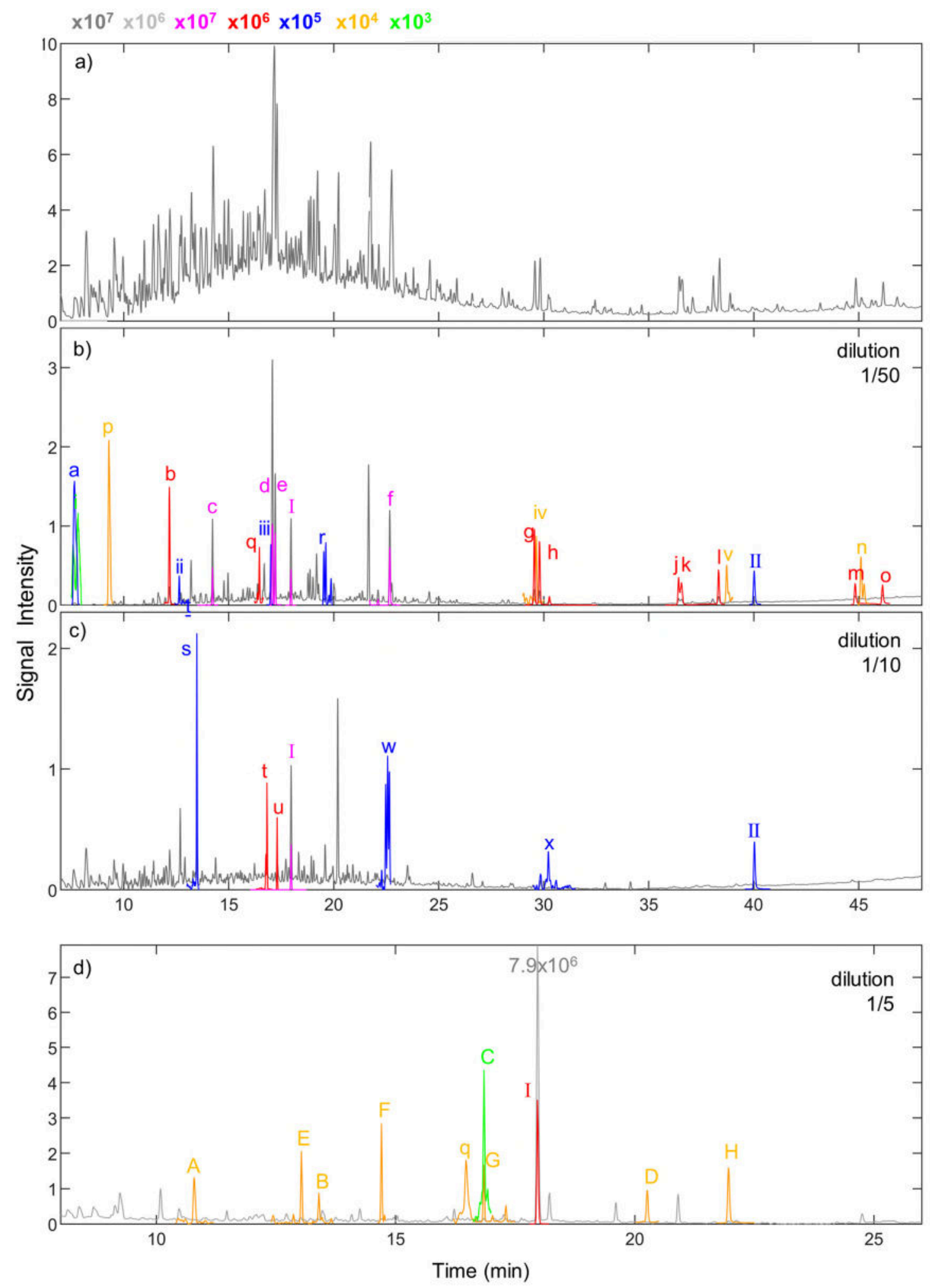

Figure 4: GC-MS chromatograms for SPE fractions of target PAH and transformation products in Soil 1 extract a) whole extract b) fraction A: PAH and OPAH c) fraction B: OHPAH d) fraction 3: COOHPAH, phenolic acids and aldehydes (note zoomed timescale). Black and grey traces refer to total ion chromatograms, while coloured represent specified analytical events from single ion monitoring traces. Specific shades relate to signal intensity order of magnitude, indicated at top left. Letters and Roman numerals refer to specific compounds identified in Table 1. Dilution levels given are relative to whole soil extract after SPE processing. 
Table 4: Recovery and quantitation of PAH and their transformation products in three test soils

\begin{tabular}{|c|c|c|c|c|c|c|c|c|c|}
\hline \multirow[t]{2}{*}{$\begin{array}{l}\text { Compound/ } \\
\text { compound group }\end{array}$} & \multicolumn{4}{|c|}{$\begin{array}{l}\text { Recovery of } 20 \mu \mathrm{g} / \mathrm{g} \text { analyte spike in extraction-SPE tests } \\
\text { with SR adjustment }\end{array}$} & \multicolumn{3}{|c|}{$\begin{array}{l}\text { Average concentration in soil } \\
\text { with } S R \text { adjustment } \mu \mathrm{g} / \mathrm{g}\end{array}$} & \multirow[t]{2}{*}{$\begin{array}{l}\text { Method LOD } \\
\mu \mathrm{g} / \mathrm{g} \text { dry soil }\end{array}$} & \multirow[t]{2}{*}{$\begin{array}{l}\text { Method LOQ }{ }^{1} \\
\mu \mathrm{g} / \mathrm{g} \text { dry soil }\end{array}$} \\
\hline & standards & Soil 1 & Soil 2 & Soil 3 & Soil 1 & Soil 2 & Soil 3 & & \\
\hline \multicolumn{10}{|l|}{ ОНРАН } \\
\hline 1-hydroxynaphthalene & $77 \pm 2$ & $42 \pm 6$ & $51 \pm 3$ & $31 \pm 2$ & $8 \pm 6 *$ & $<\mathrm{LOD}$ & $<$ LOD & 0.12 & 0.44 \\
\hline 1-hydroxyacenapthene & $89 \pm 3$ & $141 \pm 10$ & $118 \pm 6$ & $95 \pm 9$ & $23 \pm 2$ & $0.50 \pm 0.05$ & $<\mathrm{LOD}$ & 0.04 & 0.16 \\
\hline 9-hydroxyfluorene & $84 \pm 3$ & $144 \pm 7$ & $105 \pm 3$ & $91 \pm 7$ & $14 \pm 1$ & $0.19 \pm 0.01$ & $<$ LOD & 0.04 & 0.16 \\
\hline 9-hydroxyphenanthrene & $145 \pm 7$ & $72 \pm 3$ & $25 \pm 1$ & $11 \pm 1$ & $7.1 \pm 7.0 *$ & $<\mathrm{LOD}$ & $<\mathrm{LOD}$ & 0.08 & 0.32 \\
\hline 1-hydroxypyrene & $68 \pm 4$ & $81 \pm 2$ & $50 \pm 2$ & $30 \pm 3$ & $2.5 \pm 1.0$ & $<\mathrm{LOD}$ & $<\mathrm{LOD}$ & 0.12 & 0.40 \\
\hline \multicolumn{10}{|l|}{ OPAH } \\
\hline \multirow[t]{2}{*}{ 1-indanone } & $86 \pm 3$ & $\mathrm{NR}^{2}$ & $82 \pm 2$ & $65 \pm 6$ & $35 \pm 10$ & $0.57 \pm 0.03^{*}$ & $<\mathrm{LOD}$ & 0.4 & 1.4 \\
\hline & $82 \pm 6$ & $N R$ & $80 \pm 10$ & $170 \pm 140$ & $28 \pm 14$ & $0.57 \pm 0.03^{*}$ & & & \\
\hline \multirow[t]{2}{*}{ 9-fluorenone } & $101 \pm 7$ & NR & $135 \pm 7$ & $90 \pm 1$ & $140 \pm 10$ & $3.9 \pm 0.3$ & $<\mathrm{LOD}$ & 0.4 & 1.2 \\
\hline & $123 \pm 14$ & $N R$ & $140 \pm 15$ & $140 \pm 30$ & $141 \pm 14$ & $3.7 \pm 0.4$ & & & \\
\hline \multirow[t]{2}{*}{9,10 -anthraquinone } & $130 \pm 12$ & NR & $200 \pm 30$ & $115 \pm 2$ & $90 \pm 7$ & $5.8 \pm 0.5$ & $<\mathrm{LOD}$ & 0.4 & 1.4 \\
\hline & $133 \pm 9$ & $N R$ & $160 \pm 20$ & $107 \pm 1$ & $90 \pm 7$ & $5.8 \pm 0.6$ & & & \\
\hline \multicolumn{10}{|l|}{ PAH } \\
\hline \multirow[t]{2}{*}{ PAH-SR1 } & $83 \pm 2$ & NR & $125 \pm 25$ & $46 \pm 42$ & $1300 \pm 800$ & $27 \pm 1$ & $<$ LOD & 1.8 & 6.0 \\
\hline & $\begin{array}{l}79 \pm 5 \\
(85 \pm 24)\end{array}$ & $\begin{array}{l}N R \\
(82 \pm 29)\end{array}$ & $\begin{array}{l}122 \pm 14 \\
(98 \pm 11)\end{array}$ & $\begin{array}{l}80 \pm 11 \\
(91 \pm 41)\end{array}$ & $2100 \pm 140$ & $28 \pm 3$ & & & \\
\hline \multirow[t]{2}{*}{ PAH-SR2 } & $107 \pm 5$ & NR & $141 \pm 22$ & $77 \pm 11$ & $1300 \pm 400$ & $28 \pm 3$ & $<\mathrm{LOD}$ & $0.6-0.8$ & $2.4-2.6$ \\
\hline & $\begin{array}{l}130 \pm 10 \\
(81 \pm 4)\end{array}$ & $\begin{array}{l}N R \\
(177 \pm 55)\end{array}$ & $\begin{array}{l}146 \pm 31 \\
(91 \pm 7)\end{array}$ & $\begin{array}{l}118 \pm 7 \\
(79 \pm 16)\end{array}$ & $980 \pm 160$ & $33 \pm 4$ & & & \\
\hline \multirow{2}{*}{ PAH-SR3 } & $110 \pm 8$ & NR & NR & $122 \pm 5$ & $7000 \pm 500$ & $370 \pm 50$ & $<$ LOD & $0.6-1.0$ & $1.8-3.4$ \\
\hline & $\begin{array}{l}120 \pm 11 \\
(95 \pm 4)\end{array}$ & $\begin{array}{l}N R \\
(129 \pm 10)\end{array}$ & $\begin{array}{l}N R \\
(118 \pm 11)\end{array}$ & $\begin{array}{l}128 \pm 7 \\
(104 \pm 9)\end{array}$ & $5690 \pm 90$ & $330 \pm 40$ & & & \\
\hline \multirow[t]{2}{*}{ PAH-SR4 } & $142 \pm 7$ & NR & NR & $167 \pm 1$ & $1000 \pm 100$ & $150 \pm 5$ & $<\mathrm{LOD}$ & $0.2-0.2$ & $0.8-0.8$ \\
\hline & $\begin{array}{l}107 \pm 4 \\
(129 \pm 10)\end{array}$ & $\begin{array}{l}N R \\
(185 \pm 25)\end{array}$ & $\begin{array}{l}N R \\
(197 \pm 17)\end{array}$ & $\begin{array}{l}106 \pm 1 \\
(142 \pm 17)\end{array}$ & $510 \pm 60$ & $82 \pm 4$ & & & \\
\hline \multirow[t]{2}{*}{ PAH-SR5 } & $108 \pm 3$ & NR & NR & $129 \pm 5$ & $2700 \pm 200$ & $520 \pm 10$ & $0.8 \pm 0.6^{*}$ & $0.4-0.8$ & $1.2-3.0$ \\
\hline & $\begin{array}{l}120 \pm 20 \\
(94 \pm 10)\end{array}$ & $\begin{array}{l}N R \\
(109 \pm 9)\end{array}$ & $\begin{array}{l}N R \\
(117 \pm 6)\end{array}$ & $\begin{array}{l}104 \pm 9 \\
(115 \pm 12)\end{array}$ & $2400 \pm 100$ & $452 \pm 15$ & $0.6 \pm 0.5^{*}$ & & \\
\hline
\end{tabular}

${ }^{1}$ method LOD and LOQ based on instrument LOD/LOQ, all method concentration/dilution factors and $0.5 \mathrm{~g}$ soil mass; for grouped PAH a range for individual PAH is given

*estimated value: asterisked compounds include estimated values for replicates $>$ LOD, but $<$ LOQ

${ }^{2} \mathrm{NR}$ 'not representative' standard dev. of unspiked samples sufficient to mask spike contribution. For PAH, recovery of deuterated surrogate $(8 \mu \mathrm{g} / \mathrm{g}$, $\mathrm{n}=6)$ is an alternate indicator 
A search in the National Institute of Standards and Technology (NIST) library for Soil 1 extracts (70\% match, following Chibwe et al., 2017) indicated the presence of additional polyaromatic compounds (PAC) which could suggest extended utility of this SPE method for a greater number of target compounds. Fraction A also revealed the presence of alkanes, additional PAH and alkyl PAH, S- and O- heterocyclic compounds, as well as additional carbonyl substituted PAC including 2-Butyl-10H-acridin-9-one and benzanthraquinone. Fraction $\mathrm{B}$ also contained a variety of semi-polar aromatic compounds, including cresols and other alkylated phenols, additional OH-phenanthrenes, a greater number of N-heterocyclic PAC and cyano, amino- and nitro-substituted PAH, as well as PAC with multiple polar functional groups. Fraction $\mathrm{C}$ indicated the presence of additional monoaromatic aldehydes such as 3-Methyl-p-anisaldehyde and 2,5thiophenedicarboxaldehyde, as well as additional phenolic acids 4-methyl-2hydroxybenzoic acid.

\subsubsection{Quantitation of target analytes in soils}

Concentrations of target analytes in soils are summarized in Table 4. Levels of PAH were highest in Soil 1, while PAH concentrations in Soil 2 were more moderate but at the midhigh range of for industrially contaminated soils presented in Arp et al. (2014). Minimal levels of high molecular weight PAH were detected in Soil 3, which could reflect the presence of combustion materials in the urban environment; more specifically, the relative abundance of benzo[a]pyrene as a proportion of benzo[a]pyrene + chrysene totals (i.e. ratio > 0.35) may suggest the presence of coal combustion residues (Tobiszewski and Namieśnik, 2012). Concentrations of target oxygenated PAH were also highest in Soil 1 with lower levels detected in Soil 2. OPAH concentrations in Soil 1 and 2 were in line with those observed for other industrial soils with high-range and mid-range contamination levels, respectively (Arp et al., 2014). Comparison for OHPAH was 
somewhat more difficult due to the paucity of studies reporting concentrations of these compounds, but in general OHPAH concentrations here tended to be higher than those reported across soils of varying land-use histories (Pulleyblank et al., 2019). Soil 2 indicated levels that are similar to those evaluated for ERM-CC013a, obtained from a former gasworks sites in Berlin (Bandowe and Wilke, 2010), while Soil 1 indicated levels substantially higher levels than have previously been reported. This was likely related to the overall very high levels of contamination in this soil when compared to other industrial sites (Arp et al., 2014).

\section{Conclusions}

The developed SPE method using aminopropyl silica showed good performance for the separation of PAH and oxygenated PAH into relevant groups for subsequent instrumental analysis by GC-MS, while improving recovery and/or reducing materials and simplifying preparation compared to previous methods. The combined extraction+ SPE method showed strong reproducibility for the quantitation of PAH, OPAH, and most OHPAH in individual soils, and offered further qualitative information for some COOHPAH and phenolic acids and aldehydes. We demonstrated that the level of contamination and proportion of clay in the soil matrix may impact recovery at different stages of the protocol. In many cases, this may be adequately accounted for through the use of suitable deuterated surrogate compounds. The increased availability of a range of labelled oxygenated PAH would be especially useful when recovery is to be monitored throughout the full extraction method. The method presented here can be used to compare soils or to monitor changes in concentrations of these analytes in individual soils over time. In order to support the establishment of best practices for managing short- and long-term risk from oxygenated PAH at and downstream from contaminated sites, we recommend the 
continued development, adoption, and standardization of analytical protocols which include these compounds alongside parent PAH.

Acknowledgements: This work was completed as part of the REMEDIATE (Improved decision-making in contaminated land site investigation and risk assessment) H2020 Marie Skłodowska-Curie Actions (Grant agreement n. 643087). We further thank Ecologia Environmental Solutions Limited and Paddock Geo Engineering for providing the contaminated soil samples necessary for this study.

\section{References}

Abdel-Shafy, H.I., Mansour, M.S.M., 2016. A review on polycyclic aromatic hydrocarbons: Source, environmental impact, effect on human health and remediation. Egypt. J. Pet. 107$123 \mathrm{https}: / /$ doi.org/10.1016/j.ejpe.2015.03.011

Alegbeleye, O.O., Opeolu, B.O., Jackson, V.A., 2017. Polycyclic Aromatic Hydrocarbons: A Critical Review of Environmental Occurrence and Bioremediation. Environ. Manage. 60, 758-783. https://doi.org/10.1007/s00267-017-0896-2

Andersson, B.E., Lundstedt, S., Tornberg, K., Schnürer, Y., Öberg, L.G., Mattiasson, B., 2003. Incomplete degradation of polycyclic aromatic hydrocarbons in soil inoculated with woodrotting fungi and their effect on the indigenous soil bacteria. Environ. Toxicol. Chem. 22, 1238-1243. https://doi.org/10.1897/1551-5028(2003)022<1238:IDOPAH>2.0.CO;2

Andersson, J.T., Achten, C., 2015. Time to say goodbye to the 16 EPA PAHs? Toward an upto-date use of PACs for environmental purposes. Polycycl. Aromat. Compd. 35, 330-354. https://doi.org/10.1080/10406638.2014.991042

Arp, H.P.H., Lundstedt, S., Josefsson, S., Cornelissen, G., Enell, A., Allard, A.S., Kleja, D.B., 2014. Native oxy-PAHs, N-PACs, and PAHs in historically contaminated soils from Sweden, Belgium, and France: Their soil-porewater partitioning behavior, bioaccumulation in Enchytraeus crypticus, and bioavailability. Environ. Sci. Technol. 48, 11187-11195. https://doi.org/10.1021/es5034469

Avagyan, R., Nyström, R., Boman, C., Westerholm, R., 2015. Determination of hydroxylated polycyclic aromatic hydrocarbons by HPLC-photoionization tandem mass spectrometry in wood smoke particles and soil samples. Anal. Bioanal. Chem. 407, 4523-4534. https://doi.org/10.1007/s00216-015-8638-x

Bandowe, B.A.M., Wilcke, W., 2010. Analysis of polycyclic aromatic hydrocarbons and their oxygen-containing derivatives and metabolites in soils. J. Environ. Qual. 39, 1349. https://doi.org/10.2134/jeq2009.0298

Biswas, B., Sarkar, B., Rusmin, R., Naidu, R., 2015. Bioremediation of PAHs and VOCs: Advances in clay mineral-microbial interaction. Environ. Int. 85, 168-81. https://doi.org/10.1016/j.envint.2015.09.017 
Chibwe, L., Davie-Martin, C.L., Aitken, M.D., Hoh, E., Massey Simonich, S.L., 2017. Identification of polar transformation products and high molecular weight polycyclic aromatic hydrocarbons (PAHs) in contaminated soil following bioremediation. Sci. Total Environ. 599-600, 1099-1107. https://doi.org/10.1016/j.scitotenv.2017.04.190

Chibwe, L., Geier, M.C., Nakamura, J., Tanguay, R.L., Aitken, M.D., Simonich, S.L.M., 2015. Aerobic bioremediation of PAH contaminated soil results in increased genotoxicity and developmental toxicity. Environ. Sci. Technol. 49, 13889-13898. https://doi.org/10.1021/acs.est.5b00499

Cochran, R.E., Dongari, N., Jeong, H., Beránek, J., Haddadi, S., Shipp, J., Kubátová, A., 2012. Determination of polycyclic aromatic hydrocarbons and their oxy-, nitro-, and hydroxyoxidation products. Anal. Chim. Acta 740, 93-103. https://doi.org/10.1016/j.aca.2012.05.050

Gerlach, R.., Nocerino, J.M., 2003. USEPA/600/R-03/027 Guidance for obtaining representative laboratory anlaytical subsamples from particulate laboratory samples.

Hu, J., Adrion, A.C., Nakamura, J., Shea, D., Aitken, M.D., 2014. Bioavailability of (geno)toxic contaminants in polycyclic aromatic hydrocarbon-contaminated soil before and after biological treatment. Environ. Eng. Sci. 31, 176-182. https://doi.org/10.1089/ees.2013.0409

BS-EN 13654-2. 2001. Soil improvers and growing media; Determination of nitrogen. Dumas method.

BS EN 13039 2000. Soil improvers and mrowing media. Determination of organic matter content and ash.

ISO 10390, 2005. Soil Quality - Determination of pH. 7pp available at https://www.iso.org/standard/40879.html

ISO 11277, 2009. Soil quality -- Determination of particle size distribution in mineral soil material - Method by sieving and sedimentation. 34pp, available at https://www.iso.org/standard/54151.html

Jiang, Y., Brassington, K.J., Prpich, G., Paton, G.I., Semple, K.T., Pollard, S.J.T., Coulon, F., 2016. Insights into the biodegradation of weathered hydrocarbons in contaminated soils by bioaugmentation and nutrient stimulation. Chemosphere 161, 300-307. https://doi.org/10.1016/j.chemosphere.2016.07.032

Knecht, A.L., Goodale, B.C., Truong, L., Simonich, M.T., Swanson, A.J., Matzke, M.M., Anderson, K.A., Waters, K.M., Tanguay, R.L., 2013. Comparative developmental toxicity of environmentally relevant oxygenated PAHs. Toxicol. Appl. Pharmacol. 271, 266-275. https://doi.org/10.1016/j.taap.2013.05.006

Letzel, T., Pöschl, U., Wissiack, R., Rosenberg, E., Grasserbauer, M., Niessner, R., 2001. Phenyl-modified reversed-phase liquid chromatography coupled to atmospheric pressure chemical ionization mass spectrometry: A universal method for the analysis of partially oxidized aromatic hydrocarbons. Anal. Chem. 73, 1634-1645. https://doi.org/10.1021/ac001079t

Lundstedt, S., Bandowe, B.A.M., Wilcke, W., Boll, E., Christensen, J.H., Vila, J., Grifoll, M., Faure, P., Biache, C., Lorgeoux, C., Larsson, M., Frech Irgum, K., Ivarsson, P., Ricci, M., 2014. First intercomparison study on the analysis of oxygenated polycyclic aromatic hydrocarbons (oxy-PAHs) and nitrogen heterocyclic polycyclic aromatic compounds (NPACs) in contaminated soil. TrAC Trends Anal. Chem. 57, 83-92. https://doi.org/10.1016/j.trac.2014.01.007 
Lundstedt, S., Persson, Y., Öberg, L., 2006. Transformation of PAHs during ethanol-Fenton treatment of an aged gasworks' soil. Chemosphere 65, 1288-1294.

https://doi.org/10.1016/j.chemosphere.2006.04.031

Lundstedt, S., White, P.A., Lemieux, C.L., Lynes, K.D., Lambert, I.B., Öberg, L., Haglund, P., Tysklind, M., 2007. Sources, fate, and toxic hazards of oxygenated polycyclic aromatic hydrocarbons (PAHs) at PAH-contaminated sites. AMBIO A J. Hum. Environ. 36, 475485. https://doi.org/10.1579/0044-7447(2007)36[475:SFATHO]2.0.CO;2

Meyer, S., Cartellieri, S., Steinhart, H., 1999. Simultaneous determination of PAHs, heteroPAHs (N, S, O), and their degradation products in creosote-contaminated soils. Method development, validation, and application to hazardous waste sites. Anal. Chem. 71, 40234029. https://doi.org/10.1021/ac990136j

Meyer, W., Seiler, T.B., Reininghaus, M., Schwarzbauer, J., Püttmann, W., Hollert, H., Achten, C., 2013. Limited waterborne acute toxicity of native polycyclic aromatic compounds from coals of different types compared to their total hazard potential. Environ. Sci. Technol. 47, 11766-11775. https://doi.org/10.1021/es401609n

Murphy, B.T., Reilly, S.S.O., Monteys, X., Reid, B.F., Szpak, M.T., Mccaul, M. V, Jordan, S.F., Allen, C.C.R., Kelleher, B.P., 2016. The occurrence of PAHs and faecal sterols in Dublin Bay and their in fl uence on sedimentary microbial communities. MPB 106, 215 224. https://doi.org/10.1016/j.marpolbul.2016.02.066

Natural England Technical Information Note TIN037, 2008. Soil Texture. pp. 1-6. N.

Nomura, A., Jones, C.W., 2013. Amine-functionalized porous silicas as adsorbents for aldehyde abatement. ACS Appl. Mater. Interfaces 5, 5569-5577. https://doi.org/10.1021/am400810s

Obrist, D., Zielinska, B., Perlinger, J.A., 2015. Accumulation of polycyclic aromatic hydrocarbons (PAHs) and oxygenated PAHs (OPAHs) in organic and mineral soil horizons from four U.S. remote forests. Volume 134, 98-105. Chemosphere https://doi.org/10.1016/j.chemosphere.2015.03.087

Pinkart, H.C., Devereux, R., Chapman, P.J., 1998. Rapid separation of microbial lipids using solid phase extraction columns. J. Microbiol. Methods. 34, 9-15 https://doi.org/10.1016/S0167-7012(98)00060-8

Pulleyblank, C., Cipullo, S., Campo, P., Kelleher, B., Coulon, F., 2019. Analytical progress and challenges for the detection of oxygenated polycyclic aromatic hydrocarbon transformation products in aqueous and soil environmental matrices : A review transformation products in aqueous and soil. Crit. Rev. Environ. Sci. Technol. 49, 357409. https://doi.org/10.1080/10643389.2018.1547622

Schrlau, J.E., Kramer, A.L., Chlebowski, A., Truong, L., Tanguay, R.L., Simonich, S.L.M., Semprini, L., 2017. Formation of Developmentally Toxic Phenanthrene Metabolite Mixtures by Mycobacterium sp. ELW1. Environ. Sci. Technol. 51, 8569-8578. https://doi.org/10.1021/acs.est.7b01377

Schummer, C., Delhomme, O., Appenzeller, B.M.R., Wennig, R., Millet, M., 2009. Comparison of MTBSTFA and BSTFA in derivatization reactions of polar compounds prior to GC/MS analysis. Talanta 77, 1473-1482. https://doi.org/10.1016/j.talanta.2008.09.043

Tobiszewski, M., Namieśnik, J., 2012. PAH diagnostic ratios for the identification of pollution emission sources. Environ. Pollut. 162, 110-119. https://doi.org/10.1016/j.envpol.2011.10.025

Wang, X., Lin, L., Luan, T., Yang, L., Tam, N.F.Y., 2012. Determination of hydroxylated metabolites of polycyclic aromatic hydrocarbons in sediment samples by combining 
subcritical water extraction and dispersive liquid-liquid microextraction with

derivatization. Anal. Chim. Acta 753, 57-63. https://doi.org/10.1016/j.aca.2012.09.028

Woudneh, M.B., Benskin, J.P., Grace, R., Hamilton, M.C., Magee, B.H., Hoeger, G.C.,

Forsberg, N.D., Cosgrove, J.R., 2016. Quantitative determination of hydroxy polycylic aromatic hydrocarbons as a biomarker of exposure to carcinogenic polycyclic aromatic hydrocarbons. J. Chromatogr. A 1454, 93-100.

https://doi.org/10.1016/j.chroma.2016.05.057 